\title{
Suppression of lung metastases by the CD26/DPP4 inhibitor Vildagliptin in mice
}

\author{
Jae-Hwi Jang ${ }^{1}$ - Lesley Baerts ${ }^{2}$ - Yannick Waumans ${ }^{2}$ - Ingrid De Meester ${ }^{2}$. \\ Yoshito Yamada $^{1}$ - Perparim Limani ${ }^{3}$ Ignacio Gil-Bazo ${ }^{4}$. Walter Weder ${ }^{1}$. \\ Wolfgang Jungraithmayr ${ }^{1}$
}

Received: 10 February 2015 / Accepted: 24 July 2015/Published online: 2 August 2015

(C) Springer Science+Business Media Dordrecht 2015

\begin{abstract}
Metastases rather than primary cancers determine nowadays the survival of patients. One of the most common primary malignancies is colorectal cancer and this type of tumor is characterized by a high tendency to spread metastases to the lung and liver. CD26/DPP4 is a transmembrane molecule with enzymatic functions which cleaves biologically active peptides. Recently, CD26/DPP4 has become the focus of cancer research and it was shown that CD26/DPP4-positive cancer cells display increased metastatic activity. Here, we tested if the CD26/DPP4-inhibitor Vildagliptin suppresses the development and growth of mouse colorectal lung metastases. This inhibitor of CD26/DPP4 was employed on mouse (C57BL/6) colorectal lung metastases, established by intravenous injection of the syngeneic cell line MC38. For mechanistic analysis, a subcutaneous tumor model was used. The treatment with Vildagliptin significantly suppressed both,
\end{abstract}

Electronic supplementary material The online version of this article (doi:10.1007/s10585-015-9736-z) contains supplementary material, which is available to authorized users.

Wolfgang Jungraithmayr

wolfgang.jungraithmayr@usz.ch

1 Division of Thoracic Surgery, University Hospital Zurich, Raemistrasse 100, 8091 Zurich, Switzerland

2 Department of Medical Biochemistry, Department of Pharmaceutical Sciences, University of Antwerp, Universiteitsplein 1, Antwerp, Belgium

3 Department of Visceral and Transplantation Surgery, University Hospital Zurich, Raemistrasse 100, Zurich, Switzerland

4 Division of Oncology, Center for Applied Medical Research, University of Navarra, Pamplona, Spain the incidence and growth of lung metastases. Autophagy markers (LC3, p62, and ATF4) decreased, apoptosis increased (TUNEL, pH3/Ki-76), and the cell cycle regulator pCDC2 was inhibited. In conclusion, we here showed an anti-tumor effect of Vildagliptin via downregulation of autophagy resulting in increased apoptosis and modulation of the cell cycle. We therefore propose Vildagliptin for the evaluation as a new therapeutic approach for the treatment of colorectal cancer lung metastases.

Keywords CD26/DPP4 - Lung metastases - Autophagy · Apoptosis

\section{Introduction}

The lung is one of the major sites of metastasis from colorectal cancer [1]. Colorectal cancer has a high tendency to spread metastases with the second highest mortality in Europe [2]. While primary cancers are under improved control by multimodal therapy, the development of metastases is considered the most important factor for the patient's survival. If untreated, patients suffering from colorectal lung metastases have a median of 10 months survival [3].

CD26/DPP4 is a multifunctional transmembrane glycoprotein constitutively expressed on many cell types and within body fluids in a soluble form [4]. CD26/DPP4 comprises an exopeptidase enzymatic activity and cleaves off N-terminal dipeptides preferentially after Ala or Pro [5]. Furthermore, CD26/DPP4 can associate with fibroblast activation protein (FAP) and binds to extracellular matrix collagen and fibronectin [6]. During the last decade, diverse scientific disciplines have focused on CD26/DPP4, describing its involvement in the fields of immunology, 
diabetology, cardiology and cancer [7]. The unique enzyme-substrate specifications of CD26/DPP4 render several key peptides susceptible to catalytic cleavage which modulates their biological effects. The development of potent CD26/DPP4-inhibitors has led to the identification of CD26/DPP4 as a target for the successful treatment of diabetes. Currently, various commercially available CD26/DPP4-inhibitors including Vildagliptin (which we employed in this study) are routinely used in clinical practice. Remarkably, only mild side effects from the treatment with these CD26/DPP4-inhibitors have been observed up to the present [8].

A role of CD26/DPP4 in tumor biology has been suggested according to its functional and enzymatic properties in $\mathrm{T}$ cell lymphoma, mesothelioma, melanoma, renal carcinoma, colorectal cancer, and lung cancer [9-15]. Recently, a CD26/DPP4 antibody was employed as a therapeutic measure in mesothelioma and T-cell lymphoma showing down-regulation of RPB1 followed by inhibitory DNA binding of CD26/DPP4 [16-18]. In a rat study, the effect of CD26/DPP4-inhibition on colon carcinogenesis was shown by a long term treatment with the CD26/DPP4inhibitor Sitagliptin [19]. These data emphasizes the involvement of CD26/DPP4 in cancer biology.

By using an established orthotopic/simultaneous iv.-injection model of syngeneic tumor development [20-22], we report here (i) an in vitro mechanism of tumor growth inhibition related to cell cycle, (ii) the prevention of metastasis and inhibition of metastases growth from colorectal cancer by Vildagliptin in a syngeneic cell line-induced lung tumor model, and (iii) the regulation of tumor autophagy by Vildagliptin treatment, resulting in apoptosis and less cell proliferation. As Vildagliptin is in safe and effective clinical use for diabetic disease, this therapeutic approach could be a novel concept in the treatment of lung metatastic disease.

\section{Materials and methods}

\section{Animal care}

Male wild type (C57BL/6 Charles River, Germany) mice were used for all experiments $(n>5)$. Breeders of CD26/ $\mathrm{DPP}^{-/-}$mouse (based on C57BL/6 strain) were obtained from the European Mouse Mutant Archive (Orleans, France) and maintained in the Biological Central Labor, University Hospital Zurich. Animals were fed a standard laboratory diet with water and food ad libitum and were kept under constant environmental conditions. All experimental procedures were approved by the Swiss animal welfare authorities and performed in accordance with the institutional animal care guidelines.

\section{Lung metastasis mouse model}

Green fluorescence protein (GFP) labelled syngeneic mouse colorectal cancer cells (MC38: $100 \times 10^{3}$ cells/g mouse) were prepared in serum free DMEM $(100 \mu \mathrm{l})$ and injected into the inferior vena cava after middle line laparotomy under isoflurane anesthesia. After checking relevant vital signs (e.g. respiration rate, organ color) and integrity of vasculature at injection site, the abdominal wall was closed by a running suture. Vildagliptin was administered via two different routes in order to test the effect as a preventive treatment against lung metastases of colorectal cancer (pre-treatment) or a treatment for the developed lung metastases of colorectal cancer (post-treatment). Prior to injection of tumor cells (MC38, $100 \times 10^{3}$ cells/g mouse), subcutaneous pre-treatment of Vildagliptin was performed for 3 days $(100 \mathrm{mg} / \mathrm{kg})$ to test the incidence of metastasis (Suppl. 1a). Post-treatment was performed by adding Vildagliptin into drinking water $(\sim 40 \mathrm{mg} / \mathrm{kg} /$ day $)$ 10 days after tumor cell injection in order to inhibit the growth of established tumors (Suppl. 1b). Three weeks after tumor cell injection, total lungs were weighed and homogenized for quantification of GFP labeled tumor cells. Animals were sacrificed by exsanguination followed by flushing with saline and en bloc resection of thoracic organs including bilateral lungs, heart, and thymus. The whole lung was frozen for the quantification of tumor load, and heparinized plasma was collected for the measurement of CD26/DPP4 activity.

\section{Tumor cell lines}

NCI-60 cell lines (A549, H460, and Ekvx) were obtained from Charles River (Boston, USA) under material transfer agreement with the National Cancer Institute (Bethesda, USA). HT29, LLC and CT26 cell lines were purchased from American Type Culture Collection (Manassas, USA). Authenticated cell lines by both providers were stored at early passages $(<3)$ in liquid nitrogen and were used in the experiments for no more than 6 months. MC38 and GRX cell lines were kind gifts of Dr. Lubor Borsig and Dr. Radovan Borojevic, respectively. Both cell lines were stored in liquid nitrogen and were used in the experiment no more than 6 months. All cell lines were cultivated in DMEM containing $10 \% \mathrm{FBS}$ and penicillin/streptomycin within a $5 \% \mathrm{CO}_{2}$ chamber.

\section{Subcutaneous tumor model}

We employed the model of subcutaneous (sc.) tumor development by injection of the cell line sc. in order to prove the effects and mechanisms of this study how the growth of metastases is inhibited (post-treatment 
iv. model). Cell lines $(\mathrm{MC} 38)\left(1 \times 10^{6}\right.$ cells/mouse $)$ were injected under the skin of mice (back) in serum free DMEM. Vildagliptin was given in drinking water $(0.2 \mathrm{mg} / \mathrm{ml})$ for 2 weeks. Following exsanguination, the tumor was isolated from skin and weighed.

\section{DPP4 assay}

CD26/DPP4 enzymatic activity was analyzed in mouse plasma using glycyl-prolyl-4-methoxy- $\beta$-naphthylamide (Gly-Pro-4-Me- $\beta$-NA) as a fluorogenic substrate as described previously [23]. Briefly, in a 96-well plate, $10-\mu 1$ samples were mixed with $0.5 \mathrm{mM}$ Gly-Pro-4-Me- $\beta$-NA in $50 \mathrm{mM}$ Tris buffer, $\mathrm{pH} 8.3$, in a final volume of $110 \mu \mathrm{l}$. CD26/DPP4 activity was determined kinetically for $10 \mathrm{~min}$ at $37{ }^{\circ} \mathrm{C}$ by measuring the velocities of $4-\mathrm{Me}-\beta$-NA release $(\lambda \mathrm{ex}=340 \mathrm{~nm}, \lambda \mathrm{em}=430 \mathrm{~nm})$ from the substrate (all reagents are from Sigma-Aldrich, Germany).

\section{In vitro experiments}

Both mouse and human cell lines were maintained in DMEM containing $10 \%$ FBS, penicillin/streptomycin. The cell lines were seeded into 24-well plates to reach $70 \%$ confluence. Two days after cell seeding, media were exchanged with serum-free one. Twelve hours later, cells were exposed according to the experimental conditions. The treatment was performed after dilution of stock solutions including Vildagliptin, Cisplatin, Gefitinib, 3 methyladenine (3MA) (Sigma-Aldrich), SP600125 (Tocris) by serum free media (DMEM). Daily metabolic activity was assessed by the methylthiazolyldiphenyl-tetrazolium bromide (MTT, Sigma-Aldrich) assay. For western blotting assays, cell lines were prepared in $10 \mathrm{~cm}$ dishes. These experiments were triplicated.

\section{Protein expression analysis}

Samples were homogenized in lysis buffer containing a protease inhibitor cocktail (Roche Diagnostics $\mathrm{GmbH}$, Mannheim, Germany), phosphatase inhibitor cocktail 3, $50 \mathrm{mM}$ Tris, $150 \mathrm{mM} \mathrm{NaCl}, 5 \mathrm{mM}$ EDTA, and $0.5 \% \mathrm{NP}-$ 40 (Sigma-Aldrich). The protein concentration was determined using the Bradford protein assay (BioRad, Hercules, USA). Reducing SDS-PAGE was performed and samples were blotted onto a PVDF-membrane. p62 (MBL), CDC2, pCDC2, PTEN, Cleaved caspase3, LC3, ATF4, AKT, pAKT (Cell signaling), E-cadherin, N-cadherin, Vimentin (Abcam) and ID1 [24] antibodies were tested. Loading control was a rabbit anti-GAPDH (Abcam) and anti-beta actin (Sigma-Aldrich). Secondary antibody binding and detection was performed according to standard protocols with the ECL detection reagent (BioRad).

\section{Histology}

Formalin fixed and paraffin embedded samples were stained by antibodies against Ki67, p-Histon3, and GFP. TUNEL stain was used for detection of apoptotic cells within the tumor.

\section{Statistical analysis}

Data were presented as mean $\pm \mathrm{SD}$. Groups were compared with the Student t-test for unpaired samples using Prism 4.0 (GraphPad Software, San Diego, CA, USA). A two-sided $p$ value $<0.05$ was considered to be statistically significant.
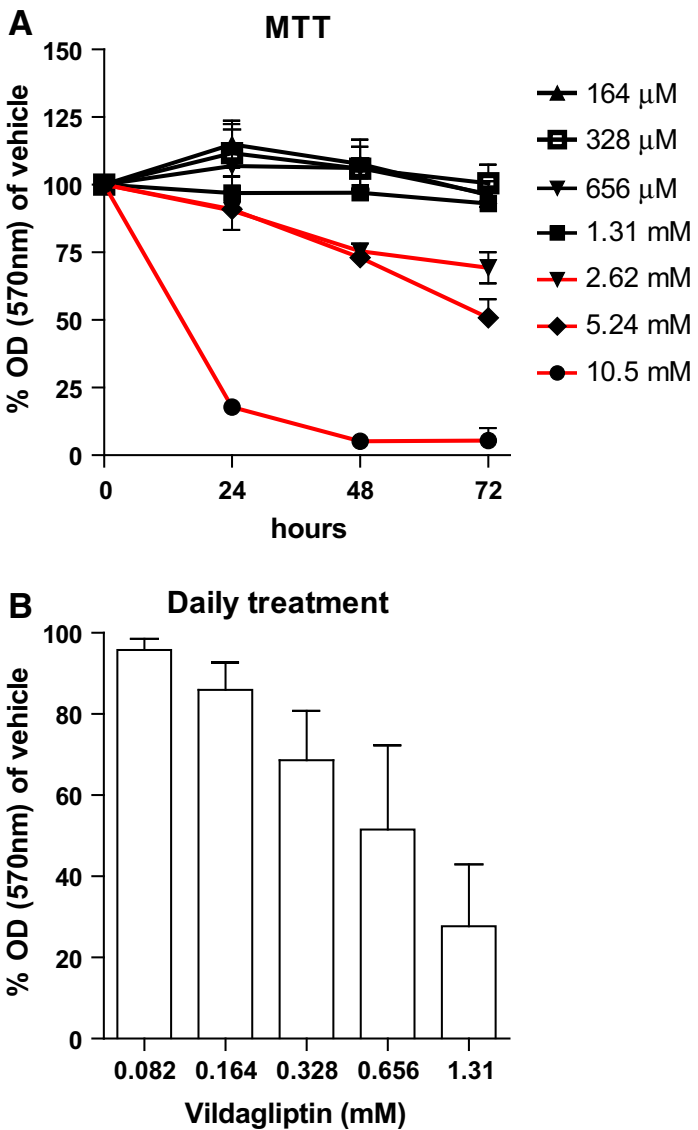

Fig. 1 In vitro cytotoxicity test of Vildagliptin. Various doses $(164 \mu \mathrm{M}-10.5 \mathrm{mM})$ of Vildagliptin were administered to the MC38 cell line grown in 24 well plates to test the metabolic activity of tumor cells. The metabolic activity was shown by MTT assay measured at 24, 48, $72 \mathrm{~h} \mathrm{(A)}$, and 7 days (B). Vildagliptin was given one time after $12 \mathrm{~h}$ of serum free medium to test the cytotoxicity during 3 days (A). The treatment of Vildagliptin showed a pronounced cytotoxicity in a dose-dependent manner, also confirmed in other cell lines (Suppl. 2). Similar to the single treatment with high doses, continued daily treatment with non-cytotoxic doses (0.082-1.31 mM) (in vivo-situation) of Vildagliptin reduced the metabolic activity of the tumor cell line MC38 in vitro (B) 


\section{Results}

\section{Cytotoxicity test of Vildagliptin in tumor cell lines}

To test the effect of Vildagliptin directly on tumor cells first in vitro, we tested different doses (from $<164 \mu \mathrm{M}$ to $10.5 \mathrm{mM}$ ) (Fig. 1A) on various cell lines with existing resistance to conventional chemotherapeutics (cisplatin and gefitinib) (Suppl. 2a). The IC50 for MC38 cell line (mouse colorectal cancer) after 3 days was $5.24 \mathrm{mM}$ (Fig. 1A). Regardless of critical mutations of KRAS, EGFR, and $B R A F$ in those cell lines (Suppl. Table 1), Vildagliptin treatment showed a cytotoxicity in a dose-dependent manner. To mimic the in vivo situation, we tested daily Vildagliptin treatment for 7 days by giving non-cytotoxic doses similar to the dose used in the in vivo experiments $(40 \mathrm{mg} / \mathrm{kg} /$ day). Interestingly, these non-cytotoxic doses of Vildagliptin (doses below $2.62 \mathrm{mM}$, see Fig. 1A) decreased the metabolic activity of MC38 cell line in vitro (Fig. 1B). This effect could be confirmed in various mouse and human cell lines (Suppl. 2). Taken together, we found a cytotoxic effect of Vildagliptin in tumor cell lines as well as after repeated treatment of non-cytotoxic doses of Vildagliptin, mimicking the in vivo situation. However, of note, there is still the possibility that under these high concentrations of Vildagliptin, also cytoplasmatic enzymes are prone to inhibition by Vildagliptin.

\section{Vildagliptin suppresses the incidence of colorectal lung metastases in mice}

Next, we aimed to prevent the development of lung metastases of colorectal cancer cells in mice by the pretreatment with Vildagliptin. Vildagliptin $(100 \mathrm{mg} / \mathrm{kg})$ or saline (vehicle) was administered for 3 days by subcutaneous injection into mice before the injection of the syngeneic cell line $(\mathrm{MC} 38)$. The cell line $\left(100 \times 10^{3}\right.$ cells $/ g$ mouse) was intravenously injected into the inferior vena cava of C57BL/6 and CD26- $6^{-1-}$ mice and harvested 1 day or three weeks after injection in order to test the metastatic activity of colorectal cancer cells. The cell line injection was performed $3 \mathrm{~h}$ after the last administration of Vildagliptin to obtain an optimal effect of the treatment towards the injected cells (Fig. 2A). One day after injection,
Fig. 2 Prevention of lung metastases by Vildagliptin pretreatment in the MC38 cell line. Prior to injection of tumor cells (MC38, $100 \times 10^{3}$ cells $/ g$ mouse), subcutaneous pretreatment of Vildagliptin was performed for 3 days $(100 \mathrm{mg} / \mathrm{kg})$ in order to test the incidence of metastasis. The CD26/DPP4 activity was measured serially 1,3 , and $5 \mathrm{~h}$ after Vildagliptin treatment $(100 \mathrm{mg} / \mathrm{kg})(\mathbf{A})(\mathrm{n}=4)$. The immunohistochemistry of GFP showed tumor cell foci one day after injection (arrow) (B), counted histologically $(\times 200)$ through all lobes of lungs from control, pre-treatment of Vildagliptin, and $\mathrm{CD} 26^{-/-}$mice $(n=3)(\mathbf{C})$. EMT markers were significantly modulated by the pre-treatment of Vildagliptin in vitro (D) (Suppl. 3a-c) $(* p<0.05 ; * * p<0.01$; $* * * p<0.001)$

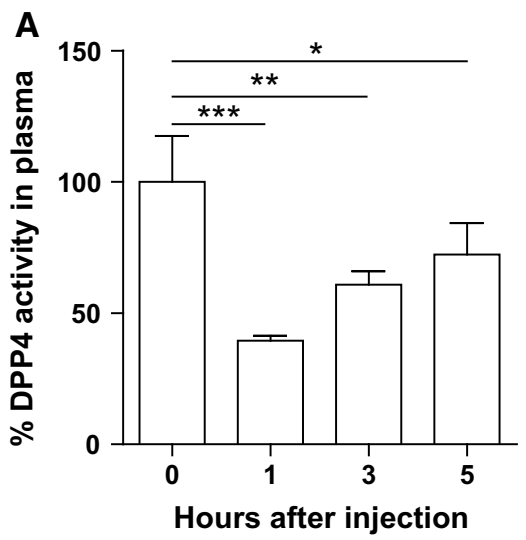

B
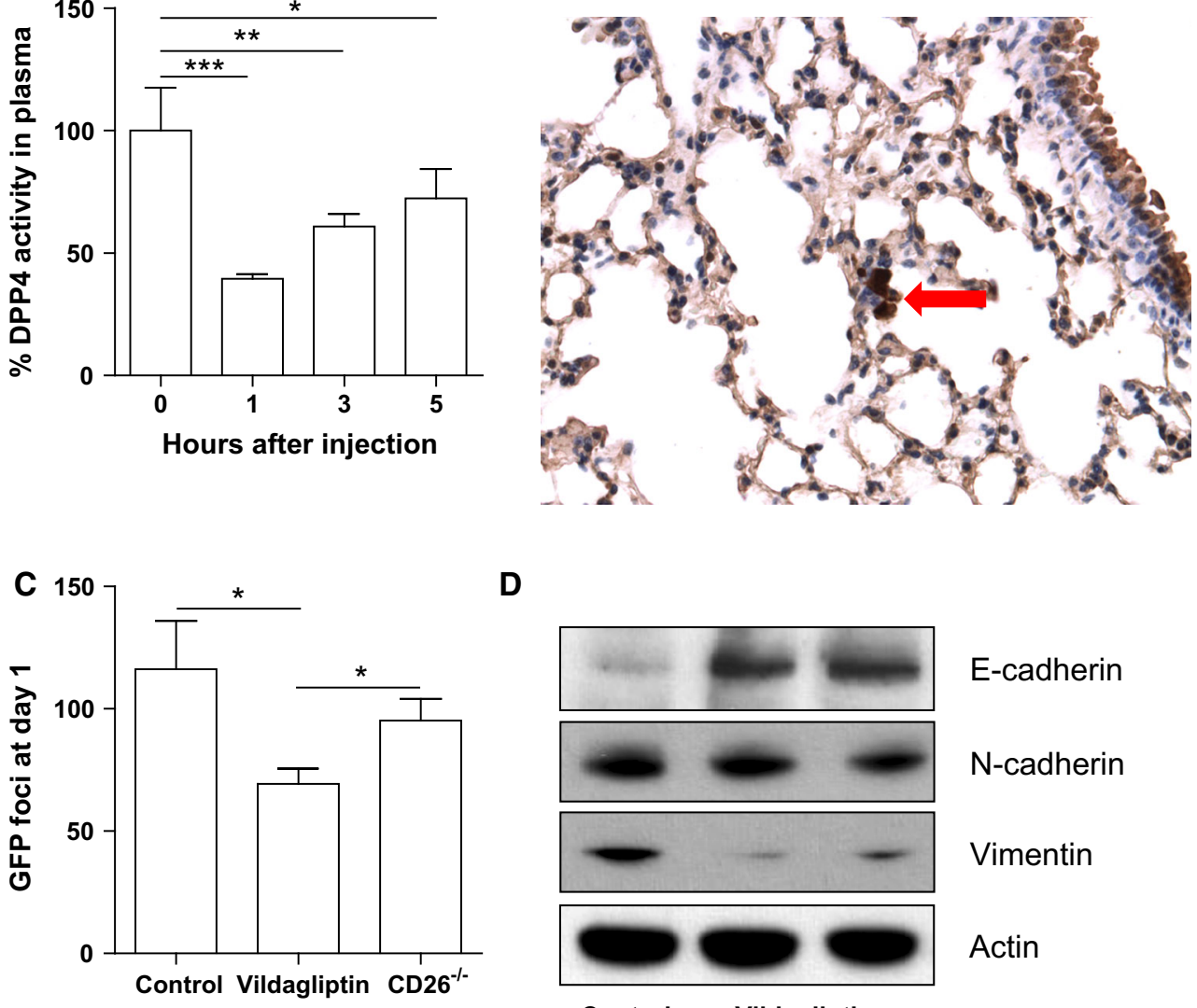

D

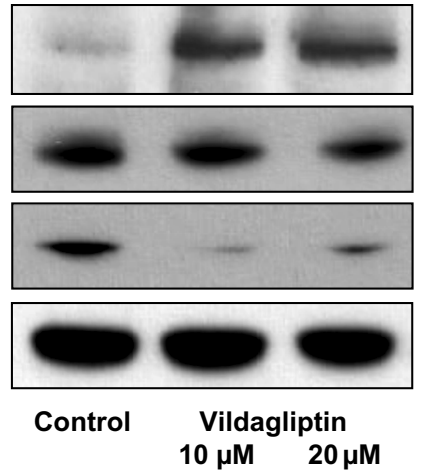

E-cadherin

$\mathrm{N}$-cadherin

Vimentin

Actin 
metastatic tumor cells were counted under the microscope $(\times 200)$ throughout all lobes of the lung (Fig. 2B, C). Here, pretreatment of Vildagliptin significantly decreased metastases. However, compared to controls, CD $26^{-/-}$mice showed a similar number of metastases. Of note, the in vitro treatment of low doses of Vildagliptin to the MC38 cell line significantly decreased markers of EMT (Fig. 2D, Suppl. 3a-c).

In order to quantify the tumor that had grown within the lung for three weeks, we homogenized the total lung and measured the fluorescence (Excitation $485 \mathrm{~nm}$ and Emission $508 \mathrm{~nm}$ ) (Fig. 3A). Tumor size estimated by fluorescence was significantly reduced by Vildagliptin pretreatment which correlated with the macroscopic observation (Fig. 3C) and the wet weight of total lung (Suppl. 3). Collectively, we found that pre-treatment of tumors with Vildagliptin prevents the incidence of colorectal cancer metastases in the lungs.

\section{Vildagliptin suppresses the growth of lung metastases in mice}

In order to test the effect of Vildagliptin against an established tumor in the lung, we induced lung tumor growth by intravenous injection of syngeneic cell line (MC38) as the metastasis model and started post-treatment of Vildagliptin ( $\sim 40 \mathrm{mg} / \mathrm{kg} /$ day in drinking water) 10 days after cell line injection. Three weeks after cell line injection, we harvested the tumor developed in the lungs. Measured GFP and total lung weight were significantly reduced by post-treatment with Vildagliptin (Fig. 3B, C). This inhibitory effect of Vildagliptin was confirmed by testing it in the subcutaneous tumor model (Fig. 4A): TUNEL positive cells were significantly increased in Vildagliptin-treated tumors compared to controls (Fig. 4B-D). In line with the growth of metastases, the size of the subcutaneously developed tumor
A
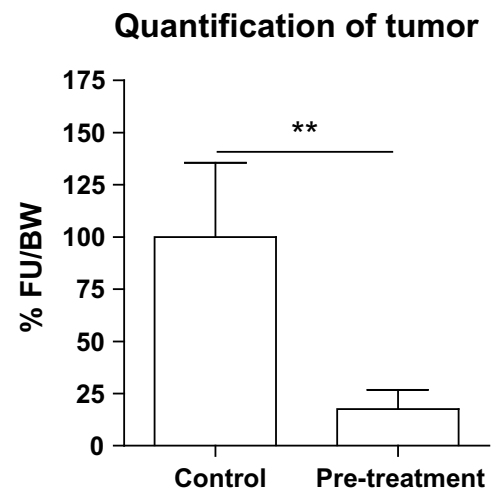

\section{B Quantification of tumor}

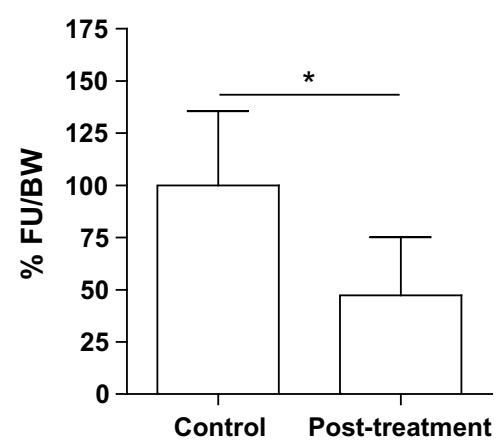

C
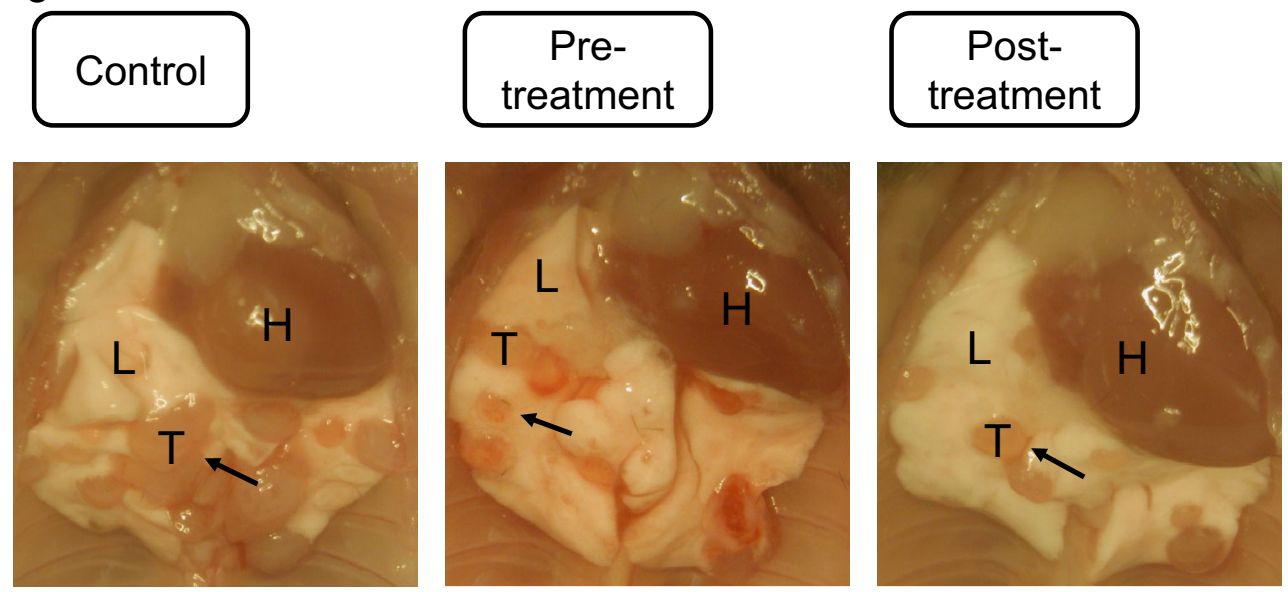

Fig. 3 Vildagliptin treatment reduced lung metastases growth. Posttreatment was performed by administering Vildagliptin into drinking water ( $\sim 40 \mathrm{mg} / \mathrm{kg} /$ day) 10 days after tumor cell injection in order to inhibit the established tumor. We performed pre-treatment of Vildagliptin $(100 \mathrm{mg} / \mathrm{kg})$ by subcutaneous injections for 3 days. Three weeks after tumor cell injection, the total lung was weighed and homogenized for quantification of GFP labeled tumor cells presented by fluorescence unit per body weight (FU/BW). Both, pre- and posttreatment of Vildagliptin significantly decreased the size of tumor in mice (A, B) without change of bodyweight within these 3 weeks (Suppl. 4). Gross anatomy of metastases developed by MC38 cell line injection is shown $(\mathbf{C}$, arrows indicate tumor) 3 weeks after injection of the MC38 cell line $\left(100 \times 10^{3}\right.$ cells/g mouse $)$ into the inferior vena cava ( $\mathrm{n}=5$ ); $L$ lung, $H$ heart, $T$ tumor. $(* * \mathrm{p}=0.0042, * \mathrm{p}=0.041)$ 
A

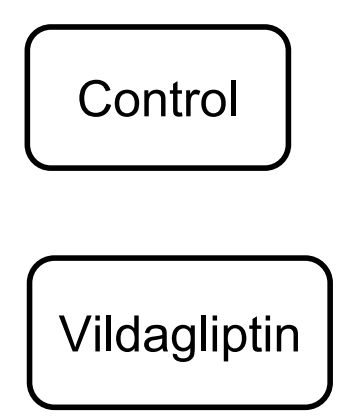

B

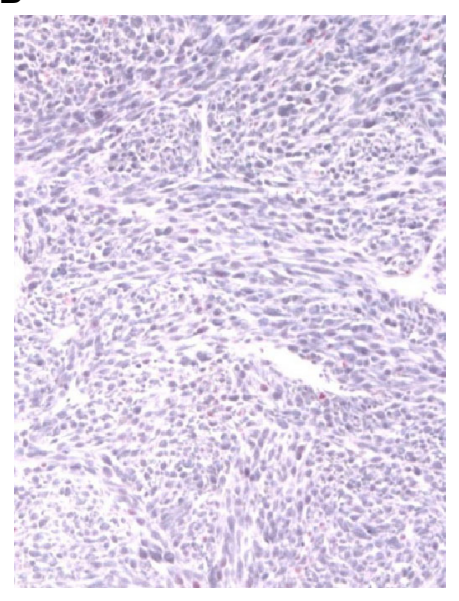

E

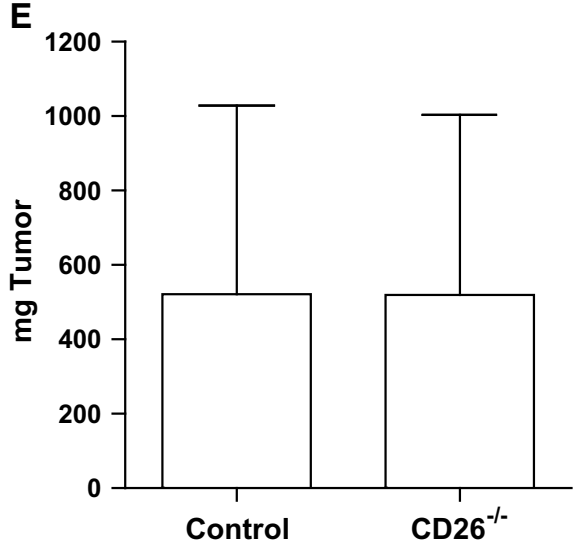

Fig. 4 Reduction of tumor size in the subcutaneously implanted MC38 tumor cell line by Vildagliptin treatment. MC38 cells $\left(1 \times 10^{6}\right.$ cells/mouse) were injected underneath the skin of syngeneic mice. Vildagliptin was administered in drinking water ( $\sim 40 \mathrm{mg} / \mathrm{kg} / \mathrm{day})$. Two weeks after tumor cell injection, the subcutaneously developed tumor was excised to measure the wet weight. Macroscopic picture of

grown in $\mathrm{CD} 26^{-/-}$mice was not changed (Fig. 4E). However, the additional treatment of Vildagliptin on $\mathrm{CD} 26^{-1-} \mathrm{KO}$ mice increased the TUNEL positivity in these

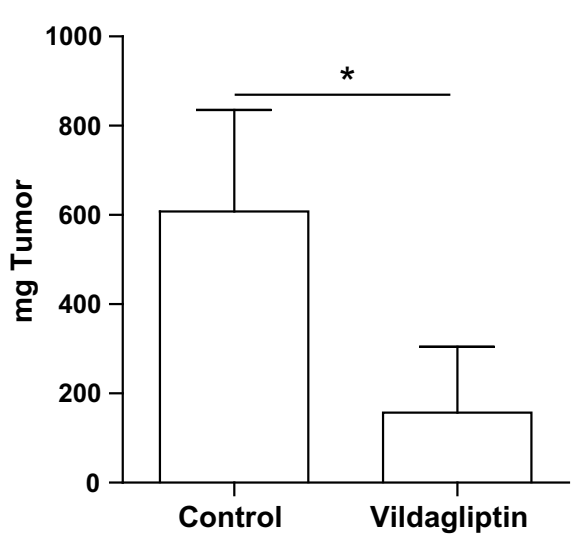

D
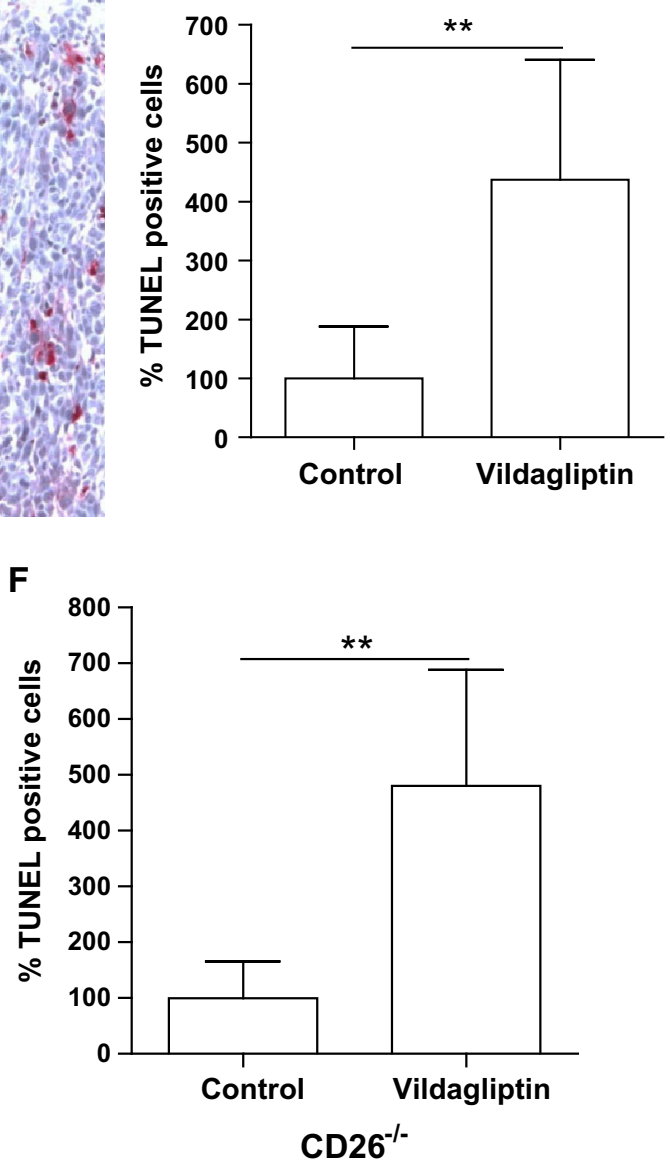

tumors separated from mice and weight of tumors (A). Compared to control (B), Vildagliptin increased apoptotic cells $(\mathbf{C}$ and $\mathbf{D})$ shown by TUNEL stain $(\mathrm{n}=4)$. Tumor in $\mathrm{CD} 26^{-1-}$ mice showed no difference from control $(\mathbf{E})$, however, the treatment of Vildagliptin on tumors developed in CD26 $6^{-1-}$ mice showed significantly more TUNEL positive cells $(\mathbf{F})(\mathrm{n}=5$ for each group $)(* \mathrm{p}=0.0113, * * \mathrm{p}=0.007)$

tumors, indicating that CD26-bearing cancer cells were indeed targeted in contrast to $\mathrm{CD} 26^{-/-}$mice which do have to a much lesser degree CD26 activity (Fig. 4F). 


\section{Vildagliptin exerts its effect via decreased autophagy}

Autophagy is recognized for its importance in maintaining tumor metabolism, resistance to chemotherapeutics, and survival under stress condition [25, 26]. Therefore, we analyzed markers that are related to autophagy in mouse tumor samples which developed upon MC38 cell line injection. The autophagy markers LC3, p62, and ATF4 were consistently decreased by Vildagliptin treatment within lung metastases and also in subcutaneously grown tumors. (Figure 5A, B; Supple. 3D-I). To test the effect of autophagy inhibition directly on the metabolic activity of cell lines in vitro, we challenged the cell lines by autophagy inhibitors in serum free condition for 3 days. Both autophagy inhibitors (3MA and SP600125) significantly decreased the metabolic activity of MC38 cell line (Fig. 5C). In parallel with the regulation of autophagy by
Vildagliptin treatment, the levels of inhibitor of differentiation 1 (ID1) and its downstream target, metabolism determinant, AKT were downregulated by Vildagliptin treatment (Suppl. 5).

\section{Vildagliptin downregulates cell cycle mediators in vitro and in vivo}

In order to elucidate mechanisms through which the effect of Vildagliptin was exerted, we tested Vildagliptin on cell cycle mediators in non-cytotoxic concentrations. Vildagliptin (82 and $164 \mu \mathrm{M}$ respectively) was incubated with the MC38 cell line. This treatment modulated the cell cycle-determining factor pCDC2 (Fig. 6A). Consistent with these in vitro results, phosphorylation of $\mathrm{CDC} 2$ was observed in subcutaneously induced tumors by Vildagliptin treatment (Fig. 6B). As a consequence of cell cycle
Fig. 5 Imbalance between autophagy and apoptosis by Vildagliptin treatment in tumor cells in vivo. The autophagy markers LC3, p62, and ATF4 were significantly decreased in tumors of lungs (A) and subcutaneous tumors (B) after MC38 cell line injection $\left(100 \times 10^{3}\right.$ cells $/ g$ mouse $)$ (Suppl. 3D-I) $(\mathrm{n}=5)$. The treatment by autophagy inhibitors (3MA, SP600125) on the MC38 cell line in vitro also showed a significant reduction of tumor cell metabolic activity after 3 days of incubation in serum free media $(\mathbf{C})$
A

Lung metastases
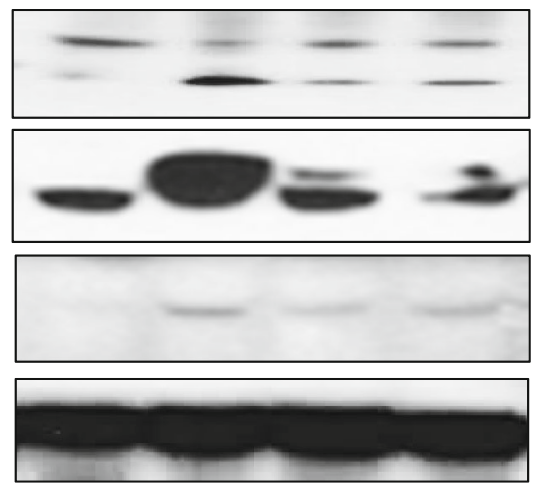

Naïve lung Control

$$
\text { Vildagliptin }
$$

C

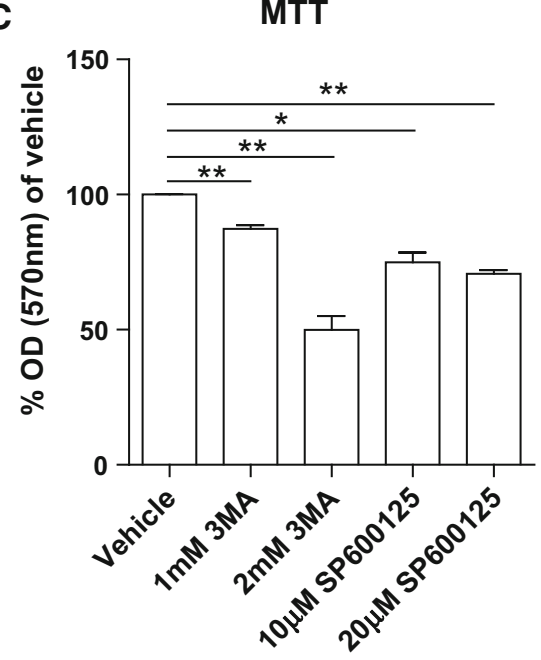

Autophagy inhibitors
B

Subcutaneous tumors

LC3

p62

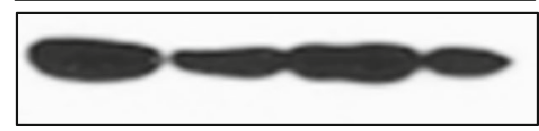

ATF4

Actin
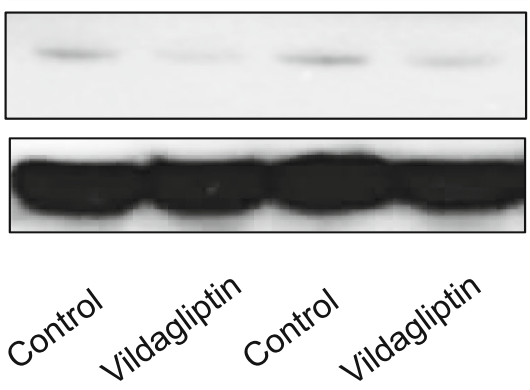
A
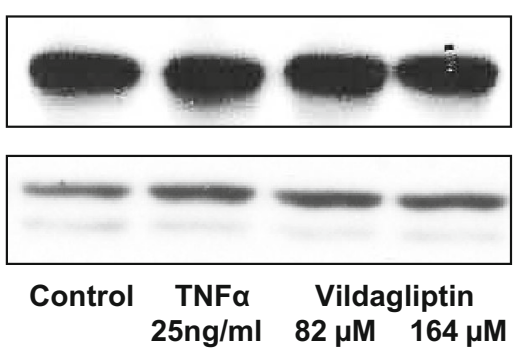
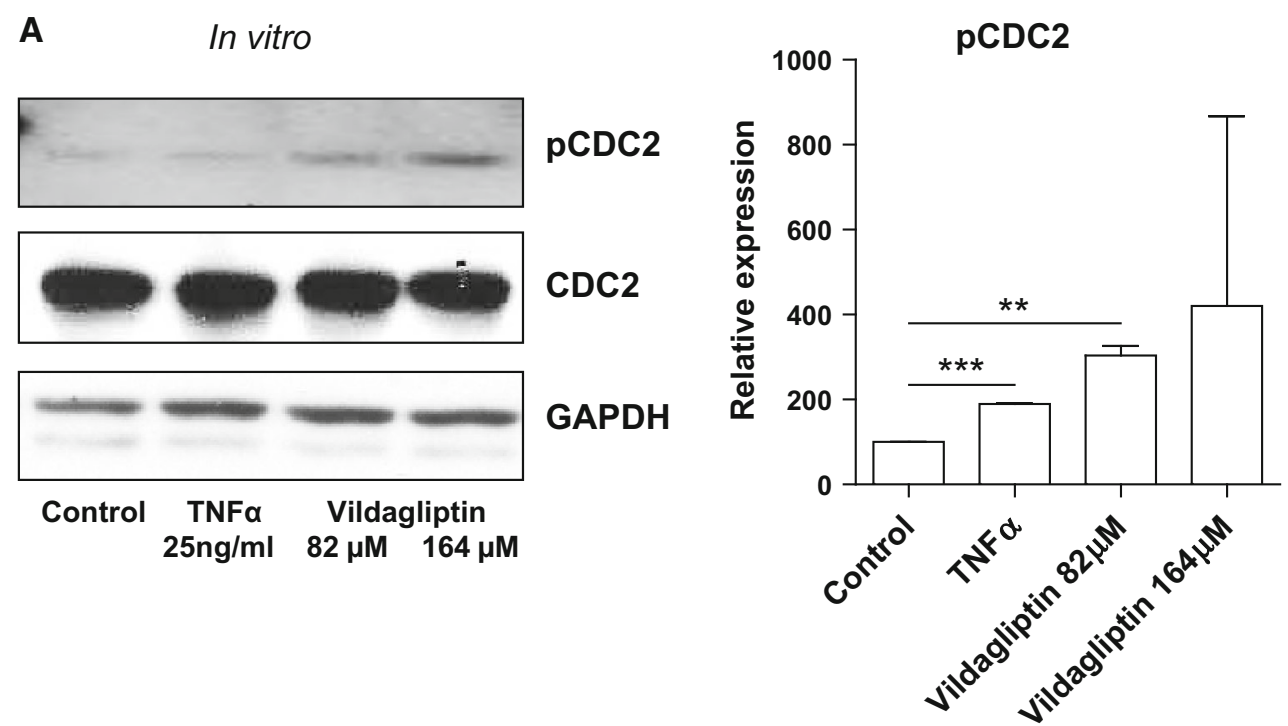

B In vivo

(subcutaneous tumors)

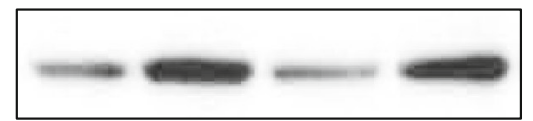

pCDC2

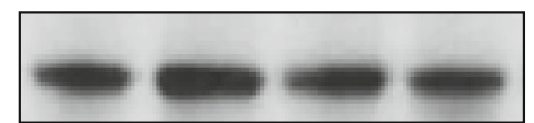

CDC2

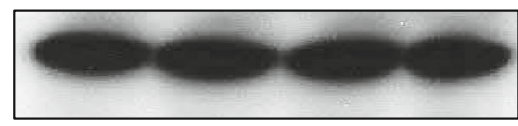

GAPDH

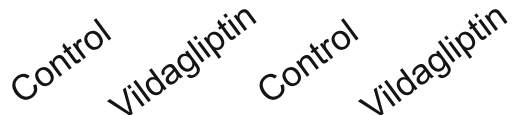

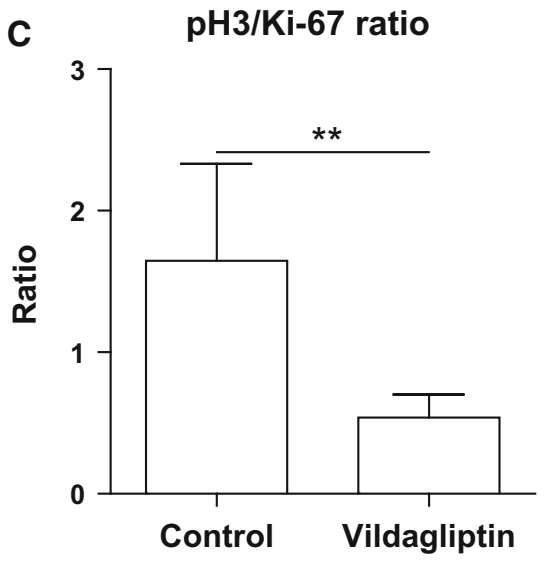

Fig. 6 Inhibition of the cell cycle by Vildagliptin treatment in vitro and in vivo. To show an effect of Vildagliptin on tumor cell growth, we added Vildagliptin to the MC38 cell line. After $8 \mathrm{~h}$ of Vildagliptin treatment, tumor cells were harvested for western blotting analysis of the G2/M phase driver pCDC2, CDC2, and GAPDH. By Vildagliptin treatment, $\mathrm{CDC} 2$ was inhibited by phosphorylation at the Tyr 15 site
(A). Consistent with the in vitro data, pCDC2 level was significantly elevated in subcutaneous tumor samples $(\mathbf{B})$. Moreover, the ratio of $\mathrm{pH} 3 / \mathrm{Ki}-67$ as a mitosis marker was significantly decreased in Vildagliptin-treated tumor samples in vivo (C) $(* \mathrm{p}<0.05$, $* * \mathrm{p}<0.01, * * * \mathrm{p}<0.001)$ 
interruption by Vildagliptin treatment, there was a significant modulation of the mitotic activity as reflected by a decreased $\mathrm{pH} 3 / \mathrm{Ki}-67$ ratio (Fig. 6C). Conclusively, cell cycle progression and proliferation in both, in vitro and in vivo, seems to be negatively regulated by Vildagliptin treatment.

\section{Discussion}

In this pre-clinical study, we found that a clinically established CD26/DPP4-inhibitor, namely Vildagliptin, has an anti-tumor effect against colorectal lung metastases in mice. Vildagliptin exerted its effects via a reduction of autophagy with the consequence of a decreased proliferation of cells and an increase of tumor apoptosis.

CD26/DPP4 have been described before to be involved in lung metastatic disease either in CD26/DPP4-deficient animal models or by using neutralizing CD26/DPP4 antibodies: when blocking CD26/DPP4 on lung endothelial cells, the interaction between lung-metastatic rat breast cancer cells and fibronectin was shown to be inhibited thus reducing at least in part the adhesion to endothelium and thereby the metastatic spread of cancer cells [27]. Alternatively, the development of lung metastases from breast adenocarcinoma cells have been described to be reduced, also via decreased adhesion of cancer cells in CD26/DPP4deficient F344 rats [28]. Pang et al. identified a subpopulation of CD26-positive cells uniformly presenting in both primary and metastatic tumors in colorectal cancer patients suffering from liver metastases, showing that CD26-positive cancer cells were associated with enhanced invasiveness and chemoresistance [13]. Authors showed in CD26positive cells that mediators of epithelial to mesenchymal transition (EMT) contribute to the invasive phenotype and metastatic capacity. These results show that if CD26/DPP4 is expressed on cells, this molecule can be targeted for metastatic disease therapy. In line with the findings of Pang et al., we could also observe a reduction of EMT markers, suggesting that the EMT status of MC38 cells were at least in part affected by Vildagliptin, consecutively diminishing the growth of metastases. However, in order to strengthen this hypothesis, the effect of Vildagliptin on the growth of metastases needs to be evaluated by more mechanistic studies unraveling the extra- or intra-cellular modulation of the metastatic machinery targeted.

With regard to the growth of existing metastases, we found that autophagy played a key role. Autophagy is an active cellular response to intra- or extra-cellular stress including stress to the endoplasmic reticulum, deprivation of nutrient, and reactive oxygen species. Autophagy in oncology includes multiple modes depending on the cancer type and its environment. On the one hand, the inhibition of autophagy has been shown to promote tumor development which has been tested in various malignancies such as lung cancer, hepatocellular cancer, and lymphoma [29, 30]. On the other hand, autophagy can prevent the development of tumor. Indeed, our data suggest that the CD26/DPP4-inhibitor Vildagliptin induces autophagy. In consequence, there was an increased apoptosis of tumor cells as reflected by increased TUNEL staining.

Another key mechanism during tumor development, at the same time as another consequence of autophagy is the reduced proliferation of tumor cells. In this context, phosphorylation (p) of $\mathrm{CDC} 2$ represents the state of arrest of cell cycle before the start of mitosis. [31] Together with increased pCDC2 levels, we found a decreased ratio of $\mathrm{pH} 3 / \mathrm{Ki} 67$, both supporting the hypothesis that the inhibition of autophagy results in cell cycle arrest.

Even though Vildagliptin is commercially employed as a CD26/DPP4-inhibitor for the safe treatment of type II diabetes, it is also known to inhibit DPP8 and 9, and FAP. [32, 33] A recent study showed a synergistic effect of Vildagliptin on the anti-leukemic action of parthenolide that was completely mediated through its inhibition of DPP8/9 and not of CD26/DPP4 [34]. Although it is well possible that the effects of Vildagliptin shown in this study are not only mediated through CD26/DPP4, we could not detect any DPP8/9 activity in the metastases samples (Supple. 6).

With regard to the employment of Vildagliptin in routine clinical use for diabetic disease since years without showing relevant side effects (50-100 mg/person/day) and in the light of the data presented in this study, Vildagliptin seems to be a promising drug to also employ in metastatic disease. Yet, the concentrations given to mice here (40 mg/kg/day) were 100 times higher than applied in diabetic patients. However, when considering the activity of CD26/DPP4 and for an effective inhibition of CD26/DPP4 activity, exactly 100 times more Vildagliptin is necessary to inhibit the same activity in humans and mice. [35].

In conclusion, Vildagliptin decreased the growth of lung metastases by downregulating autophagy, increasing apoptosis, and arresting the cell cycle. On the base of these data, we suggest Vildagliptin for further clinical evaluation for the treatment of lung metastatic disease.

Acknowledgments We thank Dr. Lubor Borsig and Dr. Radovan Borojevic for kindly providing the MC38 (GFP) and GRX cell lines. This study is supported by Swiss National Science Foundation (SNF, 2014, 310030_156876/1) and the 'Stiftung für wissenschaftliche Forschung' 2015 to WJ and by a special research fund of the University of Antwerp (FFB3551).

\section{Compliance with ethical standards}

Conflict of Interest The authors declare that they have no conflict of interest. 


\section{References}

1. Gassmann P, Kang ML, Mees ST, Haier J (2010) In vivo tumor cell adhesion in the pulmonary microvasculature is exclusively mediated by tumor cell-endothelial cell interaction. BMC Cancer 10:177

2. Ferlay J, Steliarova-Foucher E, Lortet-Tieulent J, Rosso S, Coebergh JW, Comber H, Forman D, Bray F (2013) Cancer incidence and mortality patterns in Europe: estimates for 40 countries in 2012. Eur J Cancer 49:1374-1403

3. Kim HK, Cho JH, Lee HY, Lee J, Kim J (2014) Pulmonary metastasectomy for colorectal cancer: how many nodules, how many times? World J Gastroenterol 20:6133-6145

4. Abbott CA, Baker E, Sutherland GR, McCaughan GW (1994) Genomic organization, exact localization, and tissue expression of the human CD26 (dipeptidyl peptidase IV) gene. Immunogenetics 40:331-338

5. Matheeussen V, Jungraithmayr W, De Meester I (2012) Dipeptidyl peptidase 4 as a therapeutic target in ischemia/reperfusion injury. Pharmacol Ther 136:267-282

6. Havre PA, Abe M, Urasaki Y, Ohnuma K, Morimoto C, Dang $\mathrm{NH}$ (2008) The role of CD26/dipeptidyl peptidase IV in cancer. Front Biosci 13:1634-1645

7. Lambeir AM, Durinx C, Scharpe S, De Meester I (2003) Dipeptidyl-peptidase IV from bench to bedside: an update on structural properties, functions, and clinical aspects of the enzyme DPP IV. Crit Rev Clin Lab Sci 40:209-294

8. Deacon CF (2011) Dipeptidyl peptidase-4 inhibitors in the treatment of type 2 diabetes: a comparative review. Diabetes Obes Metab 13:7-18

9. Havre PA, Abe M, Urasaki Y, Ohnuma K, Morimoto C, Dang NH (2009) CD26 expression on T cell lines increases SDF-1alpha-mediated invasion. Br J Cancer 101:983-991

10. Aoe K, Amatya VJ, Fujimoto N, Ohnuma K, Hosono O, Hiraki A, Fujii M, Yamada T, Dang NH, Takeshima Y, Inai K, Kishimoto T, Morimoto C (2012) CD26 overexpression is associated with prolonged survival and enhanced chemosensitivity in malignant pleural mesothelioma. Clin Cancer Res 18:1447-1456

11. Arwert EN, Mentink RA, Driskell RR, Hoste E, Goldie SJ, Quist S, Watt FM (2012) Upregulation of CD26 expression in epithelial cells and stromal cells during wound-induced skin tumour formation. Oncogene 31:992-1000

12. Larrinaga G, Blanco L, Sanz B, Perez I, Gil J, Unda M, Andres L, Casis L, Lopez JI (2012) The impact of peptidase activity on clear cell renal cell carcinoma survival. Am J Physiol Renal Physiol 303:F1584-F1591

13. Pang R, Law WL, Chu AC, Poon JT, Lam CS, Chow AK, Ng L, Cheung LW, Lan XR, Lan HY, Tan VP, Yau TC, Poon RT, Wong BC (2010) A subpopulation of CD26 + cancer stem cells with metastatic capacity in human colorectal cancer. Cell Stem Cell 6:603-615

14. Dimitrova M, Ivanov I, Todorova R, Stefanova N, MoskovaDoumanova V, Topouzova-Hristova T, Saynova V, Stephanova E (2012) Comparison of the activity levels and localization of dipeptidyl peptidase IV in normal and tumor human lung cells. Tissue Cell 44:74-79

15. Wesley UV, Tiwari S, Houghton AN (2004) Role for dipeptidyl peptidase IV in tumor suppression of human non small cell lung carcinoma cells. Int J Cancer 109:855-866

16. Inamoto $T$, Yamada $T$, Ohnuma $K$, Kina $S$, Takahashi $N$, Yamochi T, Inamoto S, Katsuoka Y, Hosono O, Tanaka H, Dang $\mathrm{NH}$, Morimoto C (2007) Humanized anti-CD26 monoclonal antibody as a treatment for malignant mesothelioma tumors. Clin Cancer Res 13:4191-4200
17. Yamada K, Hayashi M, Madokoro H, Nishida H, Du W, Ohnuma K, Sakamoto M, Morimoto C, Yamada T (2013) Nuclear localization of CD26 induced by a humanized monoclonal antibody inhibits tumor cell growth by modulating of POLR2A transcription. PLoS One 8:e62304

18. Ho L, Aytac U, Stephens LC, Ohnuma K, Mills GB, McKee KS, Neumann C, LaPushin R, Cabanillas F, Abbruzzese JL, Morimoto C, Dang NH (2001) In vitro and in vivo antitumor effect of the anti-CD26 monoclonal antibody 1F7 on human CD30 + anaplastic large cell T-cell lymphoma Karpas 299. Clin Cancer Res 7:2031-2040

19. Femia AP, Raimondi L, Maglieri G, Lodovici M, Mannucci E, Caderni G (2013) Long-term treatment with Sitagliptin, a dipeptidyl peptidase-4 inhibitor, reduces colon carcinogenesis and reactive oxygen species in 1,2-dimethylhydrazine-induced rats. Int J Cancer 133:2498-2503

20. Nocito A, Dahm F, Jochum W, Jang JH, Georgiev P, Bader M, Graf R, Clavien PA (2008) Serotonin regulates macrophagemediated angiogenesis in a mouse model of colon cancer allografts. Cancer Res 68:5152-5158

21. Soll C, Jang JH, Riener MO, Moritz W, Wild PJ, Graf R, Clavien PA (2010) Serotonin promotes tumor growth in human hepatocellular cancer. Hepatology 51:1244-1254

22. Lehmann K, Rickenbacher A, Jang JH, Oberkofler CE, Vonlanthen R, von Boehmer L, Humar B, Graf R, Gertsch P, Clavien PA (2012) New insight into hyperthermic intraperitoneal chemotherapy: induction of oxidative stress dramatically enhanced tumor killing in in vitro and in vivo models. Ann Surg 256:730-737; discussion 737-738

23. Jungraithmayr W, De Meester I, Matheeussen V, Baerts L, Arni S, Weder W (2012) CD26/DPP-4 inhibition recruits regenerative stem cells via stromal cell-derived factor-1 and beneficially influences ischaemia-reperfusion injury in mouse lung transplantation. Eur J Cardiothorac Surg 41:1166-1173

24. Ponz-Sarvise M, Nguewa PA, Pajares MJ, Agorreta J, Lozano MD, Redrado M, Pio R, Behrens C, Wistuba II, Garcia-Franco CE, Garcia-Foncillas J, Montuenga LM, Calvo A, Gil-Bazo I (2011) Inhibitor of differentiation-1 as a novel prognostic factor in NSCLC patients with adenocarcinoma histology and its potential contribution to therapy resistance. Clin Cancer Res 17:4155-4166

25. Cheong H, Lu C, Lindsten T, Thompson CB (2012) Therapeutic targets in cancer cell metabolism and autophagy. Nat Biotechnol 30:671-678

26. Eng CH, Abraham RT (2011) The autophagy conundrum in cancer: influence of tumorigenic metabolic reprogramming. Oncogene 30:4687-4696

27. Cheng HC, Abdel-Ghany M, Elble RC, Pauli BU (1998) Lung endothelial dipeptidyl peptidase IV promotes adhesion and metastasis of rat breast cancer cells via tumor cell surface-associated fibronectin. J Biol Chem 273:24207-24215

28. Shingu K, Helfritz A, Zielinska-Skowronek M, Meyer-Olson D, Jacobs R, Schmidt RE, Mentlein R, Pabst R, von Horsten S (2003) CD26 expression determines lung metastasis in mutant F344 rats: involvement of NK cell function and soluble CD26. Cancer Immunol Immunother 52:546-554

29. Qu X, Yu J, Bhagat G, Furuya N, Hibshoosh H, Troxel A, Rosen J, Eskelinen EL, Mizushima N, Ohsumi Y, Cattoretti G, Levine B (2003) Promotion of tumorigenesis by heterozygous disruption of the beclin 1 autophagy gene. J Clin Invest 112:1809-1820

30. Kondo Y, Kanzawa T, Sawaya R, Kondo S (2005) The role of autophagy in cancer development and response to therapy. Nat Rev Cancer 5:726-734

31. Xia Y, Lei Q, Zhu Y, Ye T, Wang N, Li G, Shi X, Liu Y, Shao B, Yin T, Zhao L, Wu W, Song X, Xiong Y, Wei Y, Yu L (2014) SKLB316, a novel small-molecule inhibitor of cell-cycle 
progression, induces $\mathrm{G} 2 / \mathrm{M}$ phase arrest and apoptosis in vitro and inhibits tumor growth in vivo. Cancer Lett 355:297-309

32. Thomas L, Eckhardt M, Langkopf E, Tadayyon M, Himmelsbach F, Mark M (2008) (R)-8-(3-amino-piperidin-1-yl)-7-but-2-ynyl3-methyl-1-(4-methyl-quinazolin-2-ylm ethyl)-3,7-dihydro-purine-2,6-dione (BI 1356), a novel xanthine-based dipeptidyl peptidase 4 inhibitor, has a superior potency and longer duration of action compared with other dipeptidyl peptidase-4 inhibitors. J Pharmacol Exp Ther 325:175-182

33. Burkey BF, Hoffmann PK, Hassiepen U, Trappe J, Juedes M, Foley JE (2008) Adverse effects of dipeptidyl peptidases 8 and 9 inhibition in rodents revisited. Diabetes Obes Metab 10:10571061

34. Spagnuolo PA, Hurren R, Gronda M, MacLean N, Datti A, Basheer A, Lin FH, Wang X, Wrana J, Schimmer AD (2013) Inhibition of intracellular dipeptidyl peptidases 8 and 9 enhances parthenolide's anti-leukemic activity. Leukemia 27:1236-1244

35. He YL, Wang Y, Bullock JM, Deacon CF, Holst JJ, Dunning BE, Ligueros-Saylan M, Foley JE (2007) Pharmacodynamics of vildagliptin in patients with type 2 diabetes during OGTT. J Clin Pharmacol 47:633-641 